\title{
AiMT
}

Advances in Military Technology

Vol. 13, No. 1 (2018), pp. 13-21

ISSN 1802-2308, eISSN 2533-4123

DOI 10.3849/aimt.01211

\section{Measurement of Pressure Field on Stationary Rotary-Wing Model for Further Computation of Chaff Cloud Bloom}

\author{
J. Žák ${ }^{1 *}$, D. Rozehnal ${ }^{2}$, J. Hnidka ${ }^{2}$, M. Mach ${ }^{1}$ and F. Dvořáček ${ }^{2}$ \\ ${ }^{I}$ Faculty of Environmental Sciences, Czech University of Life Sciences Prague, Czech Republic \\ ${ }^{2}$ Faculty of Military Technology, University of Defence in Brno, Czech Republic
}

The manuscript was received on 29 August 2017 and was accepted after revision for publication on 21 March 2018.

\begin{abstract}
:
This article describes the current situation in the area of electronic warfare. Aircraft protection can be greatly utilised not only in military but also in civilian applications. Active radar signal jamming methods are costly and therefore, aircraft protection using Chaff jamming increases efficiency, application variability and makes aircraft protection affordable. The article describes Chaff and the initial set of measurements designed for measuring aerodynamic pressure around a stationary helicopter model. This data lays foundations for the direction of further development, which is introduced at the end of the article.
\end{abstract}

\section{Keywords:}

chaff, jamming, self-defence, aerodynamic pressure

\section{Introduction}

Chaff is defined as "strips of lightweight metal or metallic materials that are dispersed in large numbers (bundles) that may be utilised in the surveillance or observation volume of radar to reflect impinging signals and simulate a true target." Chaff typically consists of strips of aluminium foil or metal-coated fibres. Each Chaff bundle may consist of thousands of individual reflectors whose lengths are related to the radar wavelength. The Chaff used in HF and VHF bands is known as "rope" (or "Rope Chaff").

Chaff can be utilised as passive electronic countermeasure techniques [1-3] in three different ways:

\footnotetext{
* Corresponding author: Faculty of Environmental Sciences, Czech University of Life Sciences Prague, Kamýcká 129, 16521 Prague 6-Suchdol, Czech Republic.

Phone: +420 7778094 05,e-mail: JanZakk@seznam.cz
} 
1) A localised Chaff puff or burst simulates the true target, and serves as a decoy to radar without Doppler clutter rejection capability. This contributes to the overload of data output $[1,3,4]$.

2) A Chaff corridor trail is utilised behind the lead aircraft in a raid. It may be fired via rockets from the lead aircraft, hiding within the corridor [1, 3].

3) A Chaff cloud is dispersed over a large area. This masks the actual attack corridor of a subsequent raid [1,3].

The Chaff elements, which are usually lightweight metal (e.g. aluminium), aluminium-plated glass or Mylar dipoles, are known as "chaff dipoles". These chaff dipoles are dispersed into the atmosphere. By reflecting radar energy, they imitate the real target with large RCS. Chaff dipoles are intended to resonate at the victim radars' frequencies. This requires the dipole length to be approximately one-half of the radar wavelength [5]. The dipoles in a package are often cut to different lengths in order to cover an entire radar band or several radar bands [1].

Methods for dispersing chaff have evolved over time, from basic ejection from aircraft windows to launching by spring-loaded or pneumatic devices.

Current methods for the dispersal of chaff are: 1) pyrotechnic charges, 2) rockets, 3) mortars, 4) air flows, 5) motors.

Chaff is ejected either mechanically or pyrotechnically. Mechanical ejection utilises small foil laminated cardboard boxes $(2.8 \times 4.8 \times 0.8$ inches $)$ which are torn open during ejection. Debris from the cardboard boxes consists of the opened box, two high-impact polystyrene plastic support pieces $(2.75 \times 4.75 \times 0.06$ inches $)$, and paper wrapping for each dipole cut. Cardboard specifications have changed from virgin Kraft paper to recycled Kraft paper, due to its biodegradable efficiency. The sealing adhesive for these boxes is an aqueous type of polyvinyl acetate and a felt spacer [6]. Fig. 1 illustrates an example of Chaff.

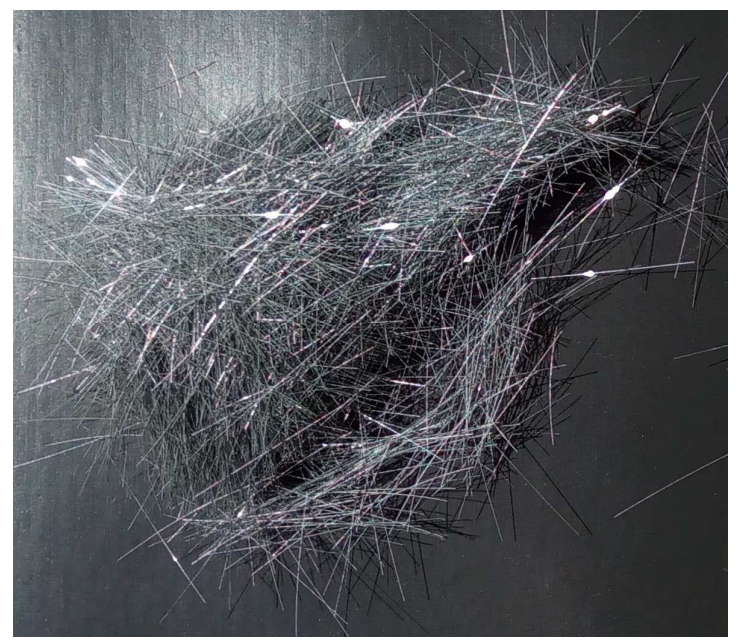

Fig. 1 Example of Chaff

During pyrotechnic ejection, the hot gases generated by an explosive impulse cartridge are applied. These gases push a small plastic piston down a chaff-filled tube, 8 inches in length, with a 1 -inch-square cross-section. A small plastic end cap is ejected, followed by the chaff fibres. The tube remains in the aircraft. The ejected debris 
consists of two 1-inch-square pieces of plastic, with a thickness of $1 / 8$ inch (piston and end cap) [6].

Chaff cartridges must demonstrate ejection of $98 \%$ of the chaff in an undamaged state. Both reliability and confidence level should be $95 \%$. Chaff cartridges must withstand any combination of environmental conditions encountered during storage, shipment, and operation [6].

Chaff is fed by motors from rolls of approximately 40 pounds, through cutters carried on aircraft to produce either bursts or a continuous stream. The continuous stream technique, called "saturation chaff", may be used by aircraft to cover a large area. Within 10 minutes, by the use of a cutter, 360 pounds of chaff from nine 40-pound rolls can be deployed. Depending on the number of aircraft and method used, these releases are able to disperse billions of fibres. Approximately $750 \mathrm{sev-}$ en-ounce boxes of chaff, each box containing up to 11 million fibres to be expelled continuously or in bursts, can be carried by the B-52 [6, 7].

\section{Example of Current Solution of Aboard Counter Measures Dispersion System}

\section{1. $\mathrm{ASO} 2 \mathrm{~V}$}

Counter measures disperser system was designed for 32 barrels at $26 \mathrm{~mm}$ diameter. Chaff and flares are available to load in. Typically Chaffs PPR - 26 are used in this CMDS. ASO $2 \mathrm{~V}$ is installed to aircrafts Su 17, Su $22 \mathrm{M} 3 / 4$, Mi 24 and it is produced in Russia [8].

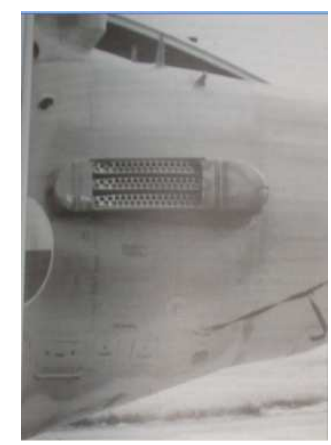

Fig. 2 CMDS ASO 2V aboard Mi-24

\subsection{Current Types of Chaffs}

Current and approachable samples of Chaffs are [8]:

- PRP -50

Fig. 3 Example of $55 \mathrm{~mm}$ cartridge 
- PPR 26-17

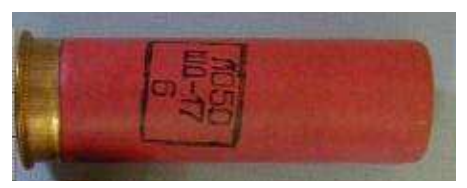

Fig. 4 Examples of Chaff PPR 26-17

- PRP 21-15

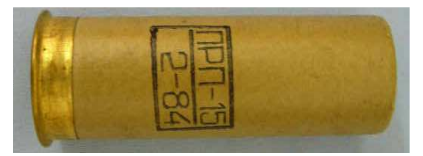

Fig. 5 Examples of Chaff PRP 21-15

\section{Pressure Field Measurement}

The primary task for measurement and subsequent simulation of Chaff dispersion in the atmosphere was to determine the pressure field in the given volume. A wind tunnel, available at the Department of Aircraft and Rocket Technology of the Faculty of Military Technology at the University of Defence in Brno, was used for this purpose.

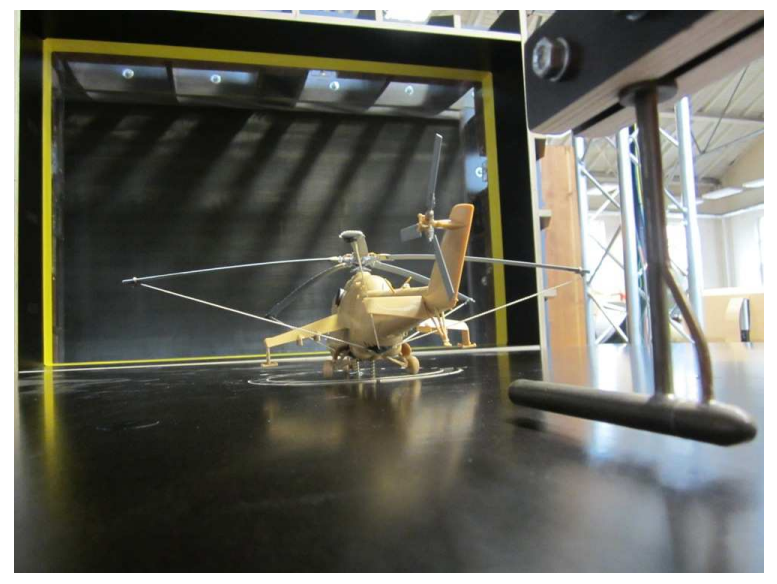

Fig. 6 Example of pressure field measurement

\subsection{Plane $x=120 \mathrm{~mm}$ behind the Helicopter Model}

The helicopter model was placed longitudinally with respect to the air flow direction. The measurement of the pressure field was taken at a distance of $x=120 \mathrm{~mm}$. The value $x=120 \mathrm{~mm}$ is defined as the distance between a point at the rear tail tip and the measuring aperture of the pitot-static probe. During the measurement process, the height $z$ was gradually altered from the modelled ground up to $160 \mathrm{~mm}$. The width $y$ under consideration was gradually altered in both directions from the axis of the helicopter model up to the distance of $240 \mathrm{~mm}$. The distance between individual measuring points in the $z$ and $y$ axes was $20 \mathrm{~mm}$. 
The measurement was made by a discrete point-by-point method using a pitot-static probe and the measured pressure values were used to determine the pressure or velocity field.

This measurement method is suitable for determining the velocity field in a stationary mode of flow around a body. By integrating pressure values from the sensing area, it is possible to get an idea about the magnitude of resistance of the flowed-around body.

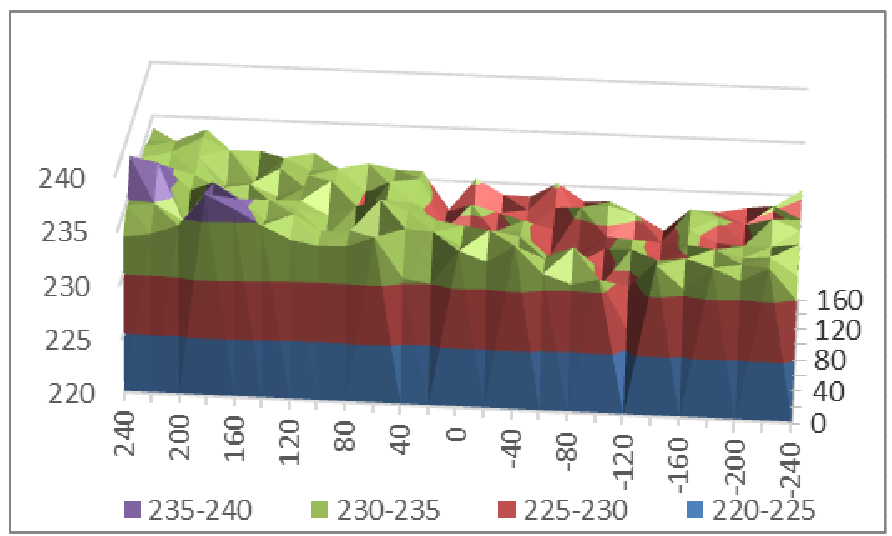

Fig. 7 Absolute values of dynamic pressure without model [Pa], $x=120 \mathrm{~mm}$

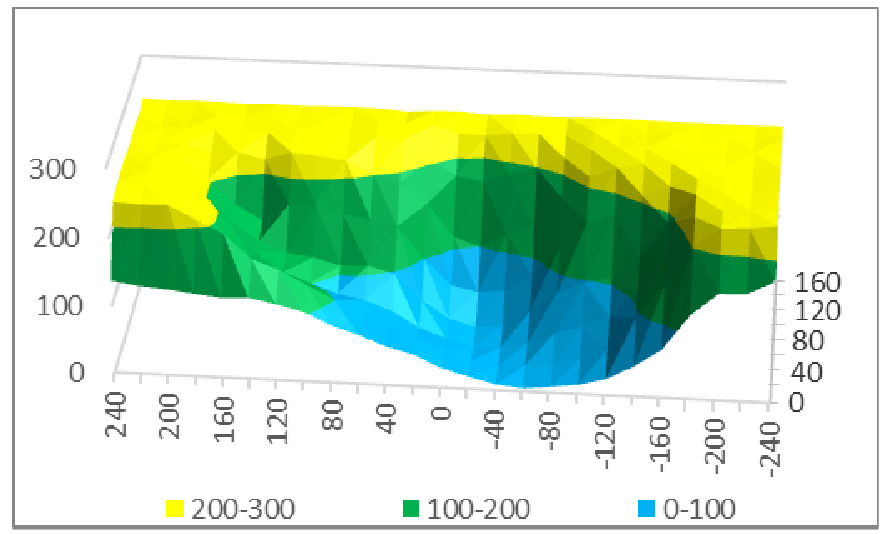

Fig. 8 Absolute values of dynamic pressure with model [Pa], $x=120 \mathrm{~mm}$

Fig. 7 describes the dynamic air pressure ${ }^{1}$ situation without the helicopter model placed. There is a noticeable decrease of values in the y axis from $240 \mathrm{~mm}$ to $-120 \mathrm{~mm}$, followed in turn by an increase up to the level of $y=-240 \mathrm{~mm}$.

\footnotetext{
${ }^{1}$ Dynamic pressure is the kinetic energy per unit volume of an air particle. Dynamic pressure is in fact one of the terms of Bernoulli's equation, which can be derived from the conservation of energy for air or fluid in motion. In simplified cases, the dynamic pressure is equal to the difference between the stagnation pressure and the static pressure [9].
} 
There is a noticeable decrease of pressure in the $z$ axis from $80 \mathrm{~mm}$ to $160 \mathrm{~mm}$ in the area of $10 \mathrm{~mm}$ to $-200 \mathrm{~mm}$ of the $y$ axis.

Fig. 8 describes the dynamic air pressure situation with the helicopter model placed. There is an apparent significant air pressure decrease in the $y$ axis from $140 \mathrm{~mm}$ to $-160 \mathrm{~mm}$ with a minimum in the area of $-60 \mathrm{~mm}$.

There is a noticeable decrease of pressure in the $z$ axis from $0 \mathrm{~mm}$ to $80 \mathrm{~mm}$ in the area of $140 \mathrm{~mm}$ to $-160 \mathrm{~mm}$ of the $y$ axis.

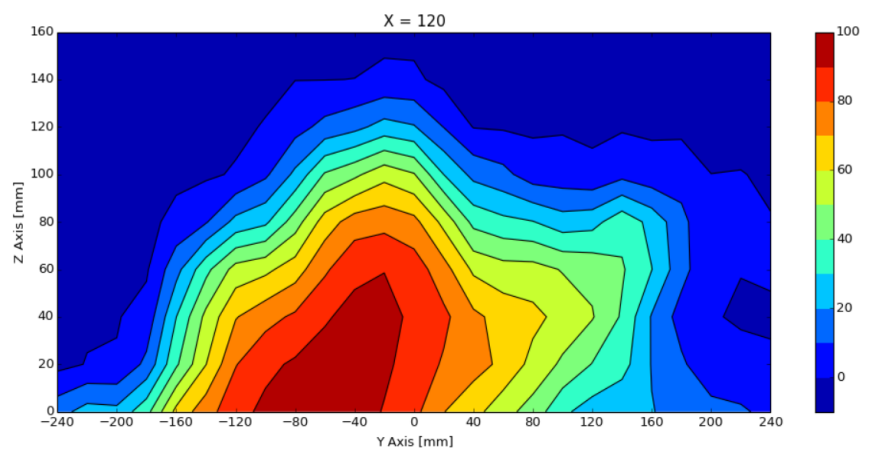

Fig. 9 Comparison in percentage of pressure field difference values, $x=120 \mathrm{~mm}$

By comparing Figs. 7 and 8 in Fig. 9 using percentage of difference values, it is apparent that the helicopter model body presents an obstacle to the air flow and forms a wake in further values of the $x$ axis. The values of pressure field diagrams in the $y$ and $z$ axes allow to compute pressure gradient that affects the Chaff dispersion.

\subsection{Plane $x=530 \mathrm{~mm}$ in front of the Helicopter Model}

The helicopter model was placed longitudinally with respect to the air flow direction. However, the direction of the flow was oriented from the tail to the nose of the model in this case. The measurement of the pressure field was made at a distance of $x=530 \mathrm{~mm}$. During the measurement process, the height $z$ was gradually altered from the modelled ground up to $160 \mathrm{~mm}$. The width $y$ under consideration was gradually altered in both directions from the axis of the helicopter model up to the distance of $240 \mathrm{~mm}$. The distance between individual measuring points in the $z$ and $y$ axes was $20 \mathrm{~mm}$.

The measurement was also made using a pitot-static probe as in the case with plane $x=120 \mathrm{~mm}$ behind the helicopter model.

Fig. 10 describes the dynamic air pressure situation without the helicopter model placed. There is a noticeable decrease of values in the $y$ axis from $240 \mathrm{~mm}$ to $-60 \mathrm{~mm}$, followed in turn by an increase up to the level of $y=-240 \mathrm{~mm}$.

There is a noticeable decrease of pressure in the $z$ axis from $40 \mathrm{~mm}$ to $120 \mathrm{~mm}$ in the area of $-40 \mathrm{~mm}$ to $-120 \mathrm{~mm}$ of the $y$ axis.

Fig. 11 describes the dynamic air pressure situation with the helicopter model placed. There is an apparent significant air pressure decrease in the $y$ axis from $60 \mathrm{~mm}$ to $-100 \mathrm{~mm}$ with a minimum in the central area, where the helicopter model is placed.

There is a noticeable decrease of pressure in the $z$ axis from $0 \mathrm{~mm}$ to $100 \mathrm{~mm}$ in the area of $60 \mathrm{~mm}$ to $-120 \mathrm{~mm}$ of the $y$ axis. 


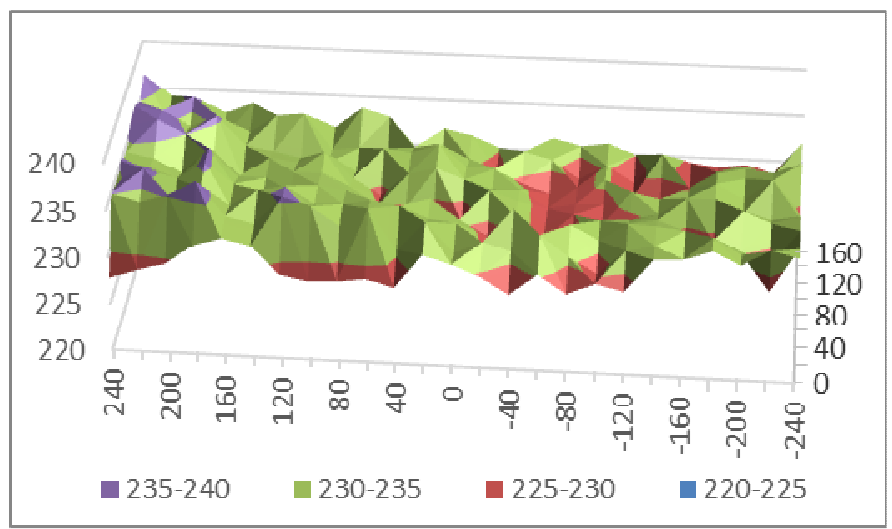

Fig. 10 Absolute values of dynamic pressure without model $[\mathrm{Pa}], x=530 \mathrm{~mm}$

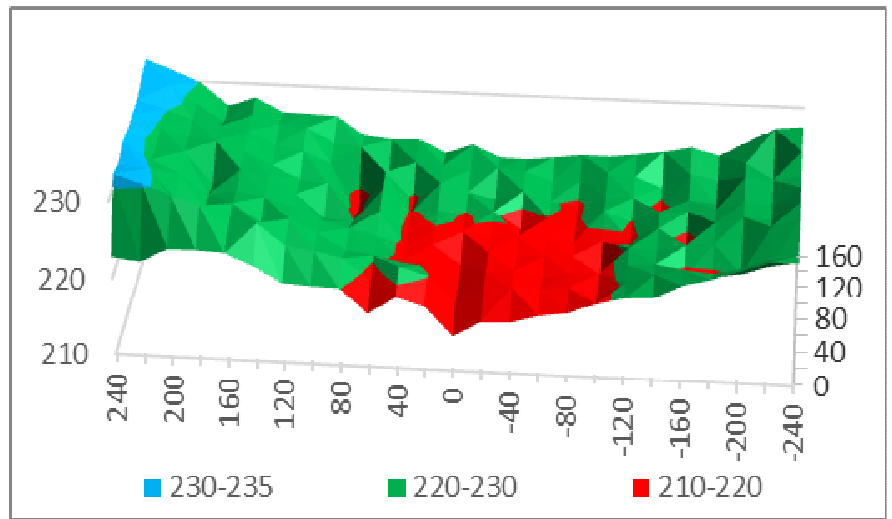

Fig. 11 Absolute values of dynamic pressure with model [Pa], $x=530 \mathrm{~mm}$

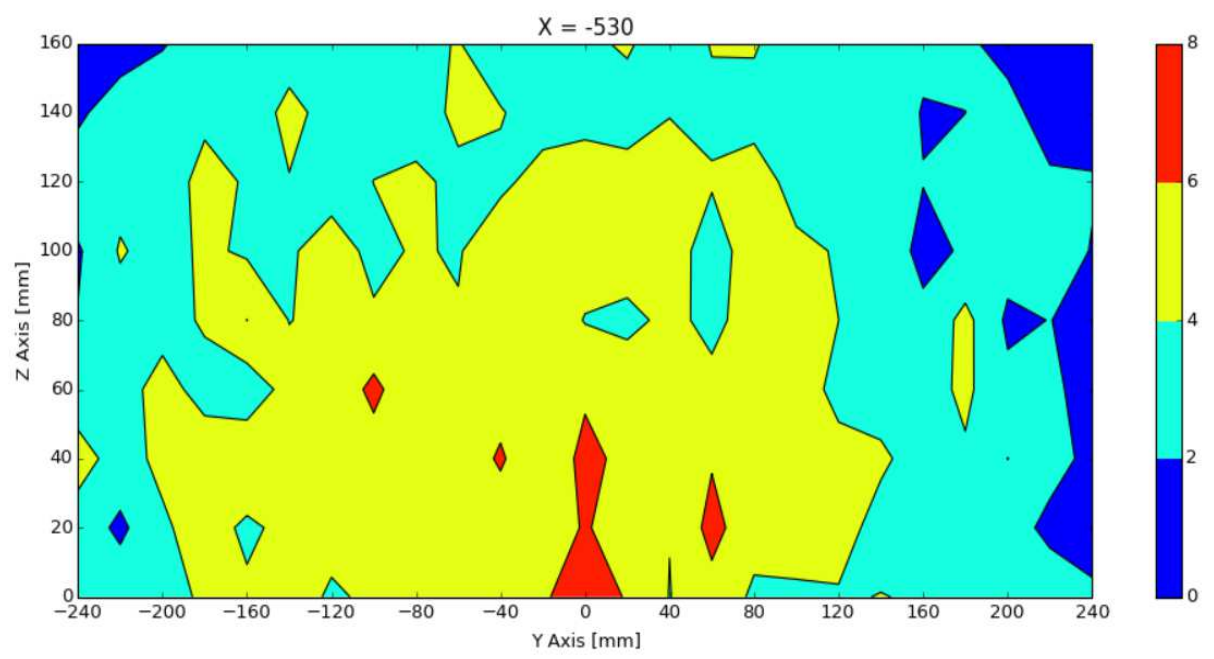

Fig. 11 Comparison in percentage of pressure field difference values, $x=530 \mathrm{~mm}$ 
By comparing Figs. 10 and 11 in Fig. 12 using percentage of difference values, it is possible to see the apparent obstacle presented by the helicopter model. This obstacle forms the region delimited by the red colour. The differences between values of Figs. 10 and 11 are within $0 \%$ to $8 \%$, and these results are very different from Fig. 9 with its $4 \%$ to $85 \%$ differences. As for Fig. 9, the values of pressure field diagrams in the $y$ and $z$ axes allow to compute pressure gradient that affects the Chaff dispersion at the distance of $530 \mathrm{~mm}$ from the helicopter model.

\section{Conclusion}

The opening part of the article described the methods of utilizing dipole reflectors and their several types that are being used nowadays. However, use of Chaff is restricted or even forbidden in many countries due to its environmental risks caused by the applied materials. The need for their use is increasing in carrying out various air missions.

The article describes the initial set of measurements designed for measuring aerodynamic pressure around a stationary helicopter model, which will then continue to the complex measurement of the turbulent air pressure matrix in the space around the rotary-wing model. The complex air pressure data will describe the initial conditions for the injection of Chaff into the complex environment and to compute its bloom characteristics. Our measurement provided new insights about the accurate values of the pressure field around the helicopter model. These values are an essential prerequisite for creating a 3D network of pressure field points around the helicopter model. If the measured values are supplied into a suitable mathematical tool, it is possible to compute more precise values of the pressure gradient between individual points. The values of pressure field changes describe the speed and direction of Chaff dispersion in open space. Our measurement confirmed the assumption concerning the changes of the pressure field with and without an obstacle and also the relationship between the pressure field changes and the distance from the obstacle. The measurement results obtained from the experiment will provide the initial data for simulating Chaff injection into the space around the model helicopter. By modelling and simulating the speed and direction of Chaff dispersion we can acquire valuable data that can be subsequently applied to computing the Radar Cross Section of the Chaff cloud.

Further developments will lead to a more detailed investigation into the subject of matter. The next step will be to enhance the pressure field with the simulation of a turbulent air flow component that will be formed by the rotor blades of a helicopter. Subsequent developments will match the simulation of the additional amount of Chaff to the air pressure field volume and include real experiments with Chaff samples. The knowledge of the dynamic air pressure field is connected to the processes of Chaff bloom in open space. This information enables the calculation of helicopter reaction time, the time determining RCS coverage of rotary-wing aircraft caused by Chaff, and the maximisation of the effect of Chaff cloud and helicopter manoeuvre against threats emitting signals in the radio-technical part of the electromagnetic spectrum.

\section{Acknowledgements}

This work was supported by the Department of Air Force and Aircraft Technology of the Faculty of Military Technology at the University of Defence in Brno under specific research SV2016 K-205, together with the Energoklastr company. 


\section{References}

[1] ČECHÁK, J. and ZAJONC, J. The Radar Electronic Warfare and Electronic Counter-countermeasure (ECCM) (in Czech). Brno: Military Academy in Brno, 2000.

[2] ČECHÁK, J. and ZAJONC, J. The Radar Electronic Warfare and Electronic Countermeasure (ECM) (in Czech). Brno: Military Academy in Brno, 2000.

[3] GILLES, R. Chaff and Flare Overview. London: BAE Systems, 2010.

[4] DARRYL, P. and CODY, L. Human and Environmental Health Issues Related to Use of Radio Frequency Chaff, Wright-Patterson Air Force Base, USA, 2014.

[5] VESELÝ, J. History of Radar and Surveillance Technology in Czech Republic. In $18^{\text {th }}$ International Radar Symposium, 2017, Prague: IEEE. DOI 10.23919/ IRS.2017.8008086.

[6] HUBER, P. Chaffs Seduction Countermeasures. Front Line Defence, vol. 8, no. 4, 2011.

[7] Air Force Doctrine Document 3-13.1: Electronic Warfare, Electronic Attack, Electronic Protection, Disruption, EW and Major Battles (Normandy Landing, Vietnam, Desert Storm). Los Gatos: Progressive Management, 2012.

[8] DVOŘÁČEK, F. and CHYTIL, R. Sources of Passive Jamming in Conditions of Army of Czech Republic. Brno: University of Defence, 2008.

[9] CLANCY, L.J. Aerodynamics. London: Pitman, 1975. 